\title{
Epithelioid angiosarcoma of the duodenum: a case report
}

\author{
Shinya Sakamoto ${ }^{1}$, Takehiro Okabayashi ${ }^{i^{*}}$ (D), Motoyasu Tabuchi ${ }^{1}$, Kenta Sui ${ }^{1}$, Takahiro Murokawa ${ }^{1}$ and \\ Jun Iwata ${ }^{2}$
}

\begin{abstract}
Background: Angiosarcomas are rare malignant tumors that arise from the endothelium of blood vessels. They occur most commonly in the skin and soft tissue, and less commonly in the breast, liver, bone, and spleen. Gastrointestinal angiosarcomas are extremely rare. Herein, we present a case of duodenal epithelioid angiosarcoma that was treated with surgical resection.
\end{abstract}

Case presentation: A 68-year-old man presented with a 1-month history of fatigue and hypotension. He visited the outpatient clinic for a routine follow-up. Laboratory examination revealed anemia. Esophagogastroduodenoscopy revealed multiple duodenal lesions with central ulceration. A biopsy showed a sheet-like arrangement of large round and spindle-shaped tumor cells that were positive for CD31. Based on the histological and immunohistochemical staining findings, an epithelioid angiosarcoma was diagnosed. Computed tomography (CT) and positron emission tomography-CT revealed no lymph node metastasis or distant metastasis. Radical subtotal stomach-preserving pancreatoduodenectomy with lymphadenectomy was performed. After removing the specimen, reconstruction was performed using the Child procedure. Grossly, two dark-red polypoid tumors were found in the second portion of the duodenum. Histological evaluation revealed proliferation of malignant round and polygonal cells arranged in sheets and spindle-like cells arranged in bundles. Vasoformative structures were recognized as slit-like spaces containing red blood cells. Immunohistochemical staining demonstrated that the tumor cells were positive for CD31. These findings confirmed the diagnosis of epithelioid angiosarcoma in the duodenum. The patient's postoperative course was uneventful. The patient was discharged on postoperative day 19 without any complications. At a follow-up examination in the outpatient clinic at postoperative 4 months, no evidence of recurrence was detected.

Conclusion: The present report describes a case of duodenal epithelioid angiosarcoma. Duodenal angiosarcomas may cause anemia and gastrointestinal bleeding. Because angiosarcomas sometimes show epithelioid cytomorphology, immunohistochemical analysis is useful for confirming the diagnosis.

Keywords: Angiosarcoma, Epithelioid angiosarcoma, Duodenal tumor

\section{Background}

Angiosarcomas are rare malignant tumors that arise from the endothelium of blood vessels. These tumors account for $1-2 \%$ of all soft tissue sarcomas [1]. They occur most commonly in the skin and soft tissue, and less commonly in the breast, liver, bone, and spleen [2]. Gastrointestinal angiosarcomas are extremely rare. Herein, we present a case of duodenal epithelioid angiosarcoma that was treated with surgical resection. We have described the pathological features of epithelioid angiosarcoma and its clinical features, including endoscopic findings.

\footnotetext{
*Correspondence: tokabaya@gmail.com

${ }^{1}$ Department of Gastroenterological Surgery at Kochi Health Sciences

Center, 2125-1 Ike, Kochi-City, Kochi 781-8555, Japan

Full list of author information is available at the end of the article
} 


\section{Case presentation}

A 68-year-old man presented with a 1-month history of fatigue and hypotension. He underwent aortic root replacement for annuloaortic ectasia 9 years prior and underwent omentum patch repair for sternal osteomyelitis after sternotomy. He had a medical history of essential hypertension and pneumoconiosis. He took aspirin, warfarin, some hypertensive drugs, and proton pump inhibiter. He visited the outpatient clinic for a routine follow-up. Laboratory investigation showed a hemoglobin level of $8.7 \mathrm{~g} / \mathrm{dL}$, a significant decrease compared with the previous value of $15.2 \mathrm{~g} / \mathrm{dL}$. After he was documented anemia, he stopped to take warfarin and continued to take aspirin for antithrombotic drugs due to cardiac surgeon's decision. Esophagogastroduodenoscopy (EDGS) revealed multiple duodenal lesions with raised red borders and central depressed areas. The anal side tumor was elevated lesions with central depressed area (Fig. 1a). The oral side tumor was ulcerative lesion with slightly elevated red border (Fig. 1b). Both tumors located in the second portion of the duodenum (Fig. 2). An abdominal computed tomography (CT) scan showed no intraluminal mass or wall thickening in the duodenum. Positron emission tomography-CT (PET-CT) demonstrated increased uptake in the duodenum (Fig. 1c). No evidence of lymph node metastasis or distant metastasis

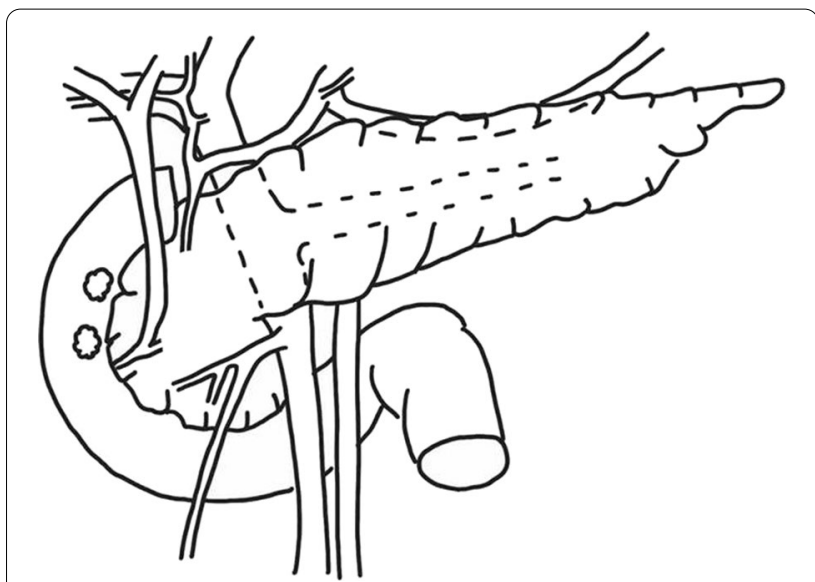

Fig. 2 Schema demonstrates localization of two duodenal lesions

was observed. A biopsy showed a sheet-like arrangement of large round and spindle-shaped tumor cells, and the tumor cells were positive for CD31. Based on the histological and immunohistochemical staining findings, an epithelioid angiosarcoma was diagnosed. Surgical resection was performed.

Exploratory abdominal surgery revealed no peritoneal metastases. The omentum, which was patched to the

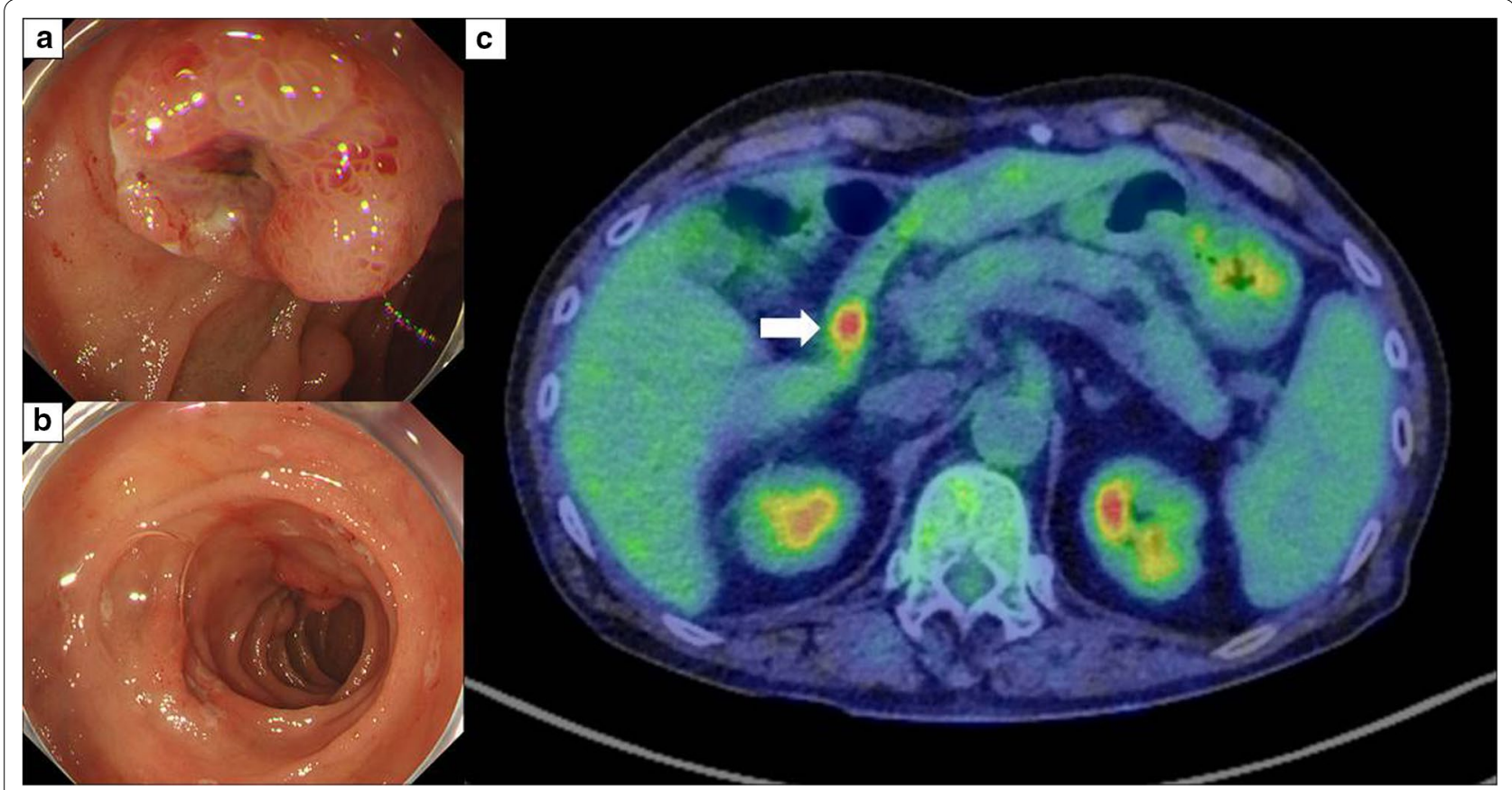

Fig. 1 Preoperative examination. a, b Esophagogastroduodenoscopy (EDGS) images: EDGS detected two reddish elevated lesions with central ulceration in the duodenum. a The anal side tumor was reddish elevated lesions with central ulceration. The oral side tumor was ulcerative lesion with slightly elevated red border. c Positron emission tomography-CT (PET-CT) image: PET-CT showed increased uptake (mean maximum standardized uptake value [SUV $\left.\left.V_{\text {max }}\right]: 6.25\right)$ of the oral side tumor in the duodenum 
sternum, was adherent to the liver. Adhesiolysis of the upper abdominal cavity was initially performed, followed by radical subtotal stomach-preserving pancreatoduodenectomy with lymphadenectomy. We dissected no. 5, $6,8 a, 8 p, 12 a, 12 p, 12 b, 13 a, 14 p, 17 a$ lymph nodes [3]. After removing the specimen, reconstruction was performed using the Child procedure (Fig. 3a).

Grossly, two dark-red polypoid tumors were found in the second portion of the duodenum. The gross appearance was slightly different from EGDS findings. The anal side tumor, measuring $1.0 \times 1.0 \mathrm{~cm}$, showed erosion, and the oral side tumor, measuring $1.4 \times 0.9 \mathrm{~cm}$, was ulceration (Fig. 3b). The lesions appeared to be centered in the submucosal layer, with expansion up to the mucosa (Fig. 4a). No spatial continuity was found between the two tumors. Histological evaluation revealed proliferation of malignant round and polygonal cells arranged in sheets and spindle-like cells arranged in bundles. Vasoformative structures were recognized as slit-like spaces containing red blood cells (Fig. 4b). No lymphatic or venous invasions were detected in both tumors. Immunohistochemical staining demonstrated that the tumor cells were positive for CD31, CK (AE1/AE3), and CAM5.2, and negative for CD34 and EMA (Fig. 4c). The lymph nodes revealed no tumor metastasis. These findings confirmed the diagnosis of epithelioid angiosarcoma in the duodenum without lymph node metastasis. The patient's postoperative course was uneventful. The patient was discharged on postoperative day 19 without any complications. At a follow-up examination in the outpatient clinic at postoperative 4 months, no evidence of recurrence was detected.

\section{Discussion}

Angiosarcoma is a rare form of malignant connective tissue neoplasm that arises from the endothelial cells of blood vessels. Tumors can arise in any part of the body, and many cases are seen on the skin of the head and neck region. Intra-abdominal angiosarcomas are rare, and the spleen and liver are the most commonly associated organs. The gastrointestinal tract is an extremely rare site for angiosarcoma. To the best of our knowledge, only five cases of primary duodenal angiosarcoma have been reported so far [4-8]. In the present case, we performed pancreatoduodenectomy for epithelioid angiosarcoma of the duodenum.

Clinically, angiosarcomas can present with various symptoms depending on their primary location. In most cases of gastrointestinal angiosarcoma, the symptoms are nonspecific, including gastrointestinal bleeding, abdominal pain, intestinal obstruction, abdominal distention, weight loss, shortness of breath, anemia, and weakness [9]. Although gastrointestinal bleeding is the most common chief complaint due to the intraluminal invasion of the tumor, cases of intraperitoneal bleeding caused by gastrointestinal angiosarcoma have also been reported

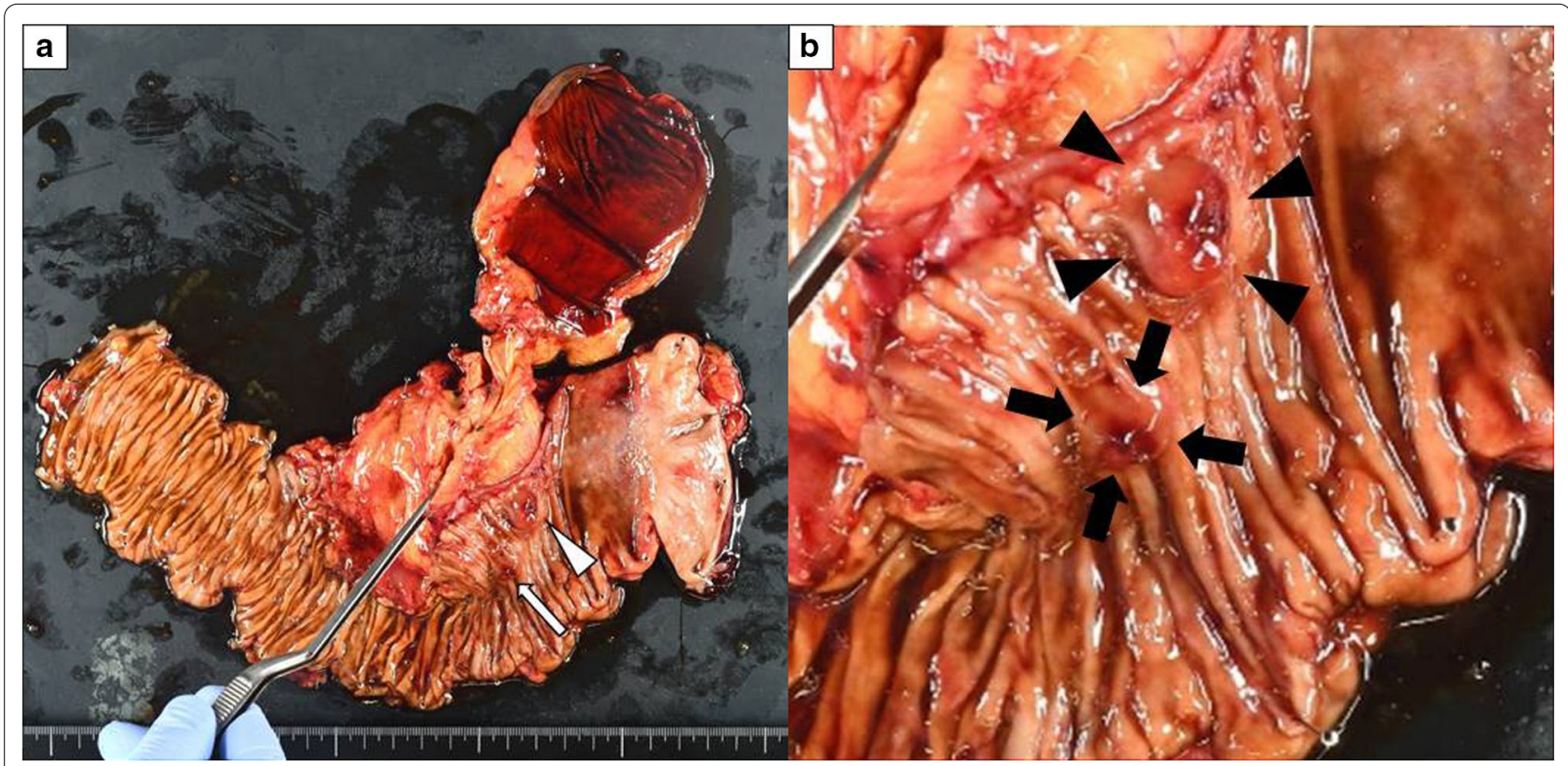

Fig. 3 Resected specimen. a Surgical specimen from subtotal stomach-preserving pancreatoduodenectomy. Two dark red polypoid tumors were found in the duodenum. Arrowhead; the oral side tumor. Arrow; the anal side tumor. b The anal side tumor (arrow) showed erosion, and the oral side tumor (arrowhead) showed ulceration 


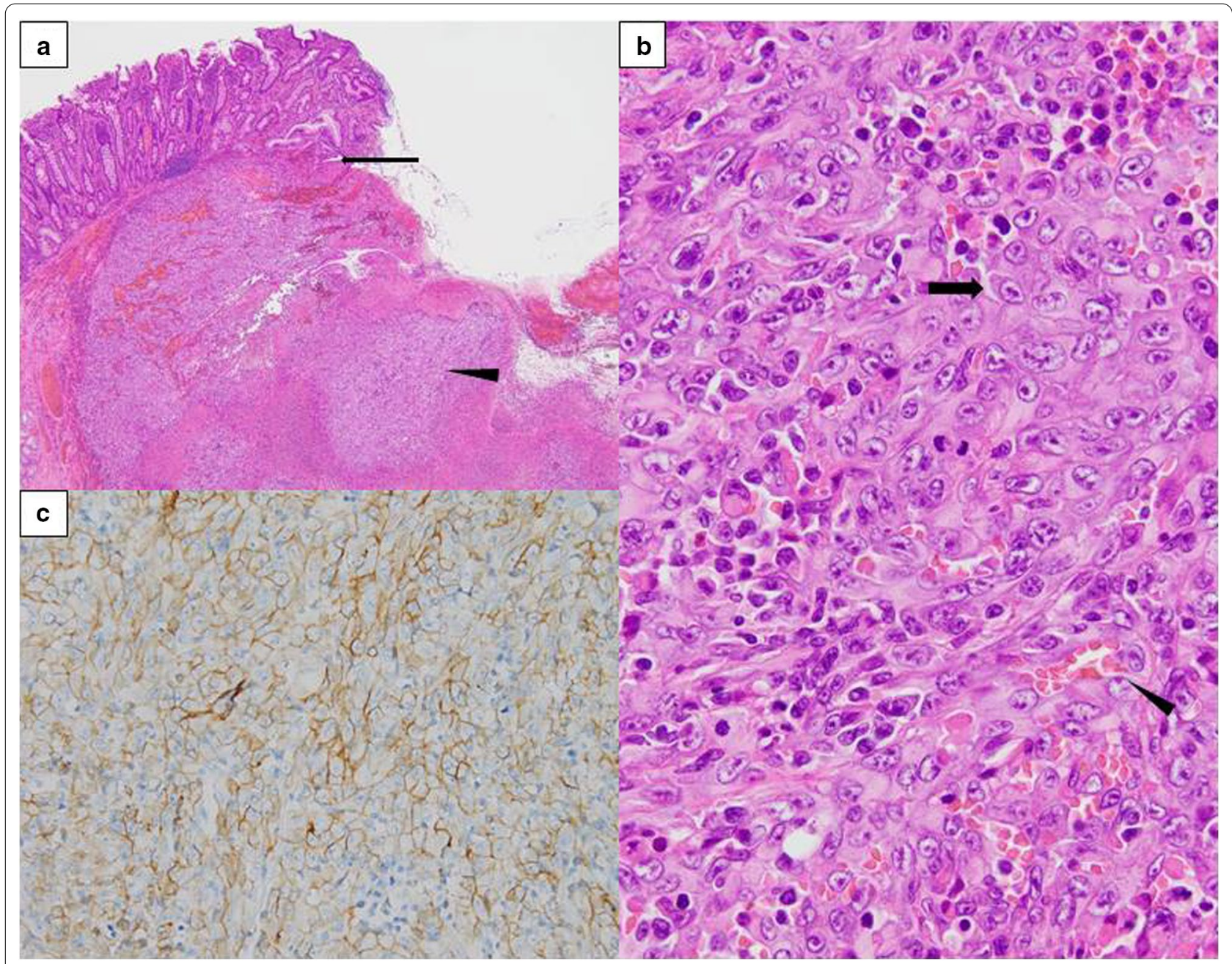

Fig. 4 Histological findings. a Microscopic image of the oral side tumor revealed that the tumor primarily arise from submucosal layer (hematoxylin-eosin [H\&E] stain; 4x). Arrow; muscularis mucosa. Arrowhead; tumor cells. b Higher power image of the oral side tumor revealed large round and polygonal cells with moderate amounts of cytoplasm arranged in sheets (arrow), and a slit-like space contained red blood cells (arrowhead) (H\&E stain; 40x) c Tumor cells were immunoreactive for CD31

$[10,11]$. Gastrointestinal angiosarcomas appear as centrally ulcerated nodules, hemorrhagic nodules, or highly erythematous or purpuric nodules [12]. In the current case, the patient presented with anemia due to gastrointestinal bleeding. EGDS revealed a reddish polypoid lesion with a central ulcer, which was similar to a previous report $[5,6]$.

The histologic features of angiosarcoma show a wide spectrum of appearances, ranging from clear vasoformative to poorly differentiated solid tumors in which the vascular nature is not readily apparent. Some angiosarcomas demonstrate epithelioid cytomorphology. Epithelioid angiosarcoma is composed of solid sheets of large, oval, or rounded epithelioid cells with abundant eosinophilic or amphophilic cytoplasm and a large, pale vesicular nucleus with a conspicuous eosinophilic nucleolus [13]. However, because of the variegated histological features, diagnosis may be difficult to achieve based on pure morphology. Immunohistochemical analysis is useful for confirming the diagnosis of epithelioid angiosarcoma. CD31, ERG, vimentin, factor VIII-related antigen, and Ulex europaeus agglutinin-1 (UEA-1) are sensitive and reliable markers for the immunohistochemical evaluation of epithelioid angiosarcoma [14-16]. In the current case, immunohistochemical workup was carried out in the initial small biopsy specimen; thus, we could diagnose this tumor as epithelioid angiosarcoma pre-operatively. Vasoformative structures and solid growth pattern of spindle-shaped cells and large polygonal epithelioidtype cells were seen in the tumors from the resected 
specimen. Immunohistochemical staining demonstrated that the tumor cells were positive for CD31. Therefore, a duodenal epithelioid angiosarcoma was diagnosed. Angiosarcoma should be kept in mind, especially when clues to angioformative morphology are noted, and a well-directed immunohistochemical workup is required even in a biopsy specimen.

Angiosarcomas are known for their rapid proliferation, aggressive infiltration, hematogenous metastasis, and relatively poor prognosis with low life expectancy. The 5 -year survival rate is $31-40 \%$ with a median overall survival of 16-31 months $[17,18]$. The primary treatment modality for angiosarcoma is surgical excision with clean margin [2]. However, even for local disease, the survey suggests that only $60 \%$ of patients survive for more than 5 years [19]. For gastrointestinal angiosarcoma cases, complete surgical resection is considered the only factor that correlates with disease-free survival [20]. Although the effectiveness of lymphadenectomy for gastrointestinal angiosarcoma remains unclear, regional lymph nodes were reported one of the most common recurrence sites for angiosarcomas of bone or soft tissue [21-23]. Therefore, gastrointestinal angiosarcoma might have potential to metastases to regional lymph node. In the current case, we performed pancreatoduodenectomy with lymphadenectomy and achieved complete surgical resection. The patient was discharged without any complications, and the postoperative course was generally favorable.

In conclusion, the present report describes a case of duodenal epithelioid angiosarcoma. Duodenal angiosarcomas may cause anemia and gastrointestinal bleeding. Because angiosarcomas sometimes show epithelioid cytomorphology, immunohistochemical analysis is useful for confirming the diagnosis.

\section{Abbreviations \\ EGDS: Esophagogastroduodenoscopy; CT: Computed tomography; PET-CT: Positron emission tomography- computed tomography; UEA-1: Ulex euro- paeus agglutinin-1.}

\section{Acknowledgements}

We would like to thank Editage (www.editage.com) for English language editing.

\section{Authors' contributions}

SS drafted the manuscript. TO and SS edited the article. TO, MT, KS, and TM performed the preoperative investigation and operation. Jl diagnosed pathologically. TO provided academic consideration. All authors read and approved the final manuscript.

\section{Funding}

This work was supported by a grant from the inochino-kikin aided THE KOCHI SHIMBUN and Kochi Broadcasting Co., Ltd. (2020-4), and Kochi Organization for Medical Reformation and Renewal grants.

\section{Availability of data and materials}

All data generated or analyzed during this study are included in the published article.

\section{Declarations}

Ethics approval and consent to participate

The ethics committee of Kochi Health Sciences Center approved the study design.

\section{Consent for publication}

Consent for publication has been obtained from the patient presented in this case report.

\section{Competing interests}

The authors declare that they have no competing interests.

\section{Author details}

${ }^{1}$ Department of Gastroenterological Surgery at Kochi Health Sciences Center, 2125-1 Ike, Kochi-City, Kochi 781-8555, Japan. ${ }^{2}$ Department of Diagnostic Pathology at Kochi Health Sciences Center, 2125-1 Ike, Kochi-City, Kochi 781-8555, Japan.

Received: 6 January 2022 Accepted: 22 February 2022

Published online: 28 February 2022

\section{References}

1. Rouhani P, Fletcher CDM, Devesa SS, Toro JR. Cutaneous soft tissue sarcoma incidence patterns in the U.S.: an analysis of 12,114 cases. Cancer. 2008;113:616-27.

2. Young RJ, Brown NJ, Reed MW, Hughes D, Woll PJ. Angiosarcoma. Lancet Oncol. 2010;11:983-91.

3. Japan Pancreas Society. Classification of pancreatic carcinoma. 4th English ed. Tokyo: Kanehara \& Co., Ltd.; 2017.

4. Al Ali J, Ko HH, Owen D, Steinbrecher UP. Epithelioid angiosarcoma of the small bowel. Gastrointest Endosc. 2006;64:1018-21.

5. Chen JL, Mok KT, Tseng HH, Wang BW, Liu SI, Chen CW. Duodenal angiosarcoma: an unusual cause of severe gastrointestinal bleeding. J Chin Med Assoc. 2007;70:352-5.

6. Mignogna C, Simonetti S, Galloro G, Magno L, de Cecio R, Insabato L. Duodenal epithelioid angiosarcoma: immunohistochemical and clinical findings. A case report. Tumori. 2007:93:619-21.

7. Coumaros D, Tsesmeli N. Epithelioid angiosarcoma in the duodenal bulb. Endoscopy. 2009:41(SUPPL. 2):232.

8. Benedict M, Gibson J, Zhang X. Epithelioid angiosarcoma: an unusual cause of gastrointestinal bleeding. Int J Surg Pathol. 2019;27:277-9.

9. Ni Q, Shang D, Peng H, Roy M, Liang G, Bi W, et al. Primary angiosarcoma of the small intestine with metastasis to the liver: a case report and review of the literature. World J Surg Oncol. 2013;11(1):242.

10. el Chaar M, McQuay N. Sigmoid colon angiosarcoma with intraperitoneal bleeding and early metastasis. J Surg Educ. 2007;64:54-6.

11. Lo TH, Tsai MS, Chen TA. Angiosarcoma of sigmoid colon with intraperitoneal bleeding: case report and literature review. Ann R Coll Surg Engl. 2011;93:91-3

12. Saad A, Cappell MS, Amin M. Endoscopic findings with Gl angiosarcoma correspond with the propensity of these vascular tumors to cause $\mathrm{Gl}$ bleeding: two case reports and review of the literature. Dig Dis Sci. 2013;58:1797-801.

13. Fletcher CDM. Diagnostic histopathology of tumors. 4th ed. Amsterdam: Elsevier; 2007.

14. Sulliva HC, Edgar MA, Cohen C, Kovach CK, HooKim K, Reid MD. The utility of ERG, CD31 and CD34 in the cytological diagnosis of angiosarcoma: an analysis of 25 cases. J Clin Pathol. 2015;68:44-50.

15. Fletcher CD, Beham A, Bekir S, Clarke AM, Marley NJ. Epithelioid angiosarcoma of deep soft tissue: a distinctive tumor readily mistaken for an epithelial neoplasm. Am J Surg Pathol. 1991;15:915-24.

16. Wu J, Li X, Liu XP. Epithelioid angiosarcoma: a clinicopathological study of 16 Chinese cases. Int J Clin Exp Pathol. 2015;8:3901-9.

17. Buehler D, Rice SR, Moody JS, Rush P, Hafez GR, Attia S, et al. Angiosarcoma outcomes and prognostic factors: a 25 -year single institution experience. Am J Clin Oncol Cancer Clin Trials. 2013;37:473-9. 
18. Fury MG, Antonescu CR, van Zee K, Brennan ME, Maki RG. A 14-year retrospective review of angiosarcoma: clinical characteristics, prognostic factors, and treatment outcomes with surgery and chemotherapy. Cancer J. 2005;11:241-7.

19. Abraham JA, Hornicek FJ, Kaufman AM, Harmon DC, Springfield DS, Raskin KA, et al. Treatment and outcome of 82 patients with angiosarcoma. Ann Surg Oncol. 2007;14:1953-67.

20. Allison KH, Yoder BJ, Bronner MP, Goldblum JR, Rubin BP. Angiosarcoma involving the gastrointestinal tract: a series of primary and metastatic cases. Am J Surg Pathol. 2004;28:298-307.

21. Mark RJ, Poen JC, Tran LM, Fu YS, Juillard GF. Angiosarcoma. A report of 67 patients and a review of the literature. Cancer. 1996;77:2400-6.

22. Meis-Kindblom JM, Kindblom LG. Angiosarcoma of soft tissue: a study of 80 cases. Am J Surg Pathol. 1998;22:683-97.

23. Pawlik TM, Paulino AF, McGinn CJ, Baker LH, Choen DS, Morris JS, et al. Cutaneous an- giosarcoma of the scalp: a multidisciplinary approach. Cancer. 2003;98:1716-26.

\section{Publisher's Note}

Springer Nature remains neutral with regard to jurisdictional claims in published maps and institutional affiliations.

\section{Submit your manuscript to a SpringerOpen ${ }^{\circ}$ journal and benefit from:}

- Convenient online submission

- Rigorous peer review

- Open access: articles freely available online

- High visibility within the field

- Retaining the copyright to your article

Submit your next manuscript at $\boldsymbol{\sim}$ springeropen.com 